\title{
MECANISMOS DIGITAIS E SEMIÓTICOS DOS POPULISMOS CONTEMPORÂNEOS (PARTE 2) - UMA APRESENTAÇÃO
}

\section{DIGITAL AND SEMIOTIC MECHANISMS OF CONTEMPORARY POPULISMS (PART 2) - A PRESENTATION}

\section{Daniel do Nascimento e Silva ${ }^{*, * *}$}

Este dossiê de Trabalhos em Linguística Aplicada, um periódico do campo dos estudos linguísticos aplicados, reúne trabalhos interessados em compreender as transformações da política contemporânea, dos modos de disciplinar sujeitos e linguagem e das relações sociais trazidas pelas novas infraestruturas de comunicação. Esta é a segunda e última parte deste dossiê dedicado aos populismos; reunimos aqui os dez artigos aprovados em língua portuguesa. A primeira parte do dossiê reuniu textos em inglês e espanhol.

Nesta segunda parte do dossiê, alguns trabalhos reunidos abordam o problema mais amplo do populismo digital (Rodrigues \& Ferreira, Viscardi, Andrade \& Marinho), outros abordam discursos de ódio ligados à ascensão do populismo reacionário no Brasil (Biar \& Paschoal, Mercuri \& Lima-Lopes, Silva), um deles se dedica a detalhar a infraestrutura neoliberal das redes digitais (Lopes) e outros dois se debruçam sobre affordances digitais que estão na base da política contemporânea no Brasil e Estados Unidos da América (Vallada, Ferreira \& Vasconcelos).

Em sua influente proposição epistêmica, Luiz Paulo da Moita Lopes (2006, p. 14) escreveu que uma boa definição de Linguística Aplicada é que este é um campo interessado em "criar inteligibilidade sobre problemas sociais em que a linguagem desempenha um papel importante". Eu não tive outro objetivo em mente senão este quando propus um número especial a Viviane Veras, a editora chefe do periódico. Ela e eu partilhamos da crença de que os recursos de um periódico de referência

\footnotetext{
* Universidade Federal de Santa Catarina, UFSC, SC, Brasil.dnsfortal@gmail.com

** Programa Interdisciplinar de Pós-Graduação em Linguística Aplicada, Universidade Federal do Rio de Janeiro.

Orcid: http://orcid.org/0000-0002-6098-5185
} 
em Linguística Aplicada no Brasil, situado numa coleção rigorosa e inovadora de revistas de acesso livre como o Scielo, poderiam ser mobilizados com o objetivo de convidar pesquisadores/as do campo aplicado a criarem inteligibilidade sobre as disjunções políticas no mundo atual. Nos últimos dez anos, grandes transformações afetaram as democracias em todo o mundo: os Estados Unidos deixaram de ser representados por um laureado com o Prêmio Nobel da Paz para serem liderados por uma celebridade bilionária que diz poder apertar o botão da bomba atômica quando quiser; o Reino Unido deixou um grande bloco econômico e político multilateral pela incerteza de uma política redefinida, circunscrita (e supostamente mais homogênea e soberana); o Brasil está lentamente abandonando conquistas democráticas de sua constituição cidadã para mergulhar no passado autoritário que se recusou a rever.

Embora essa curta lista de novidades e perplexidades nos diga respeito enquanto cidadãos e cidadãs, nossas atuais dificuldades também apontam para importantes problemas de investigação, e estamos aqui para responder a eles como pesquisadores/as. Estudos em sociolinguística, pragmática, linguística aplicada, antropologia, sociologia e outros campos têm chamado a atenção para o fato de as ansiedades que mencionei acima - bem como as transformações atuais da globalização - estarem cada vez mais sendo afetadas pela digitalização. As tecnologias digitais de comunicação são muito mais do que "facilitadoras da interatividade e mobilidade das pessoas"; elas alteram "a própria natureza dessa interatividade, transformando o sentido de lugar, pertencimento e relações sociais" (JACQUEMET, 2019, p. 153). A pesquisa sobre formas emergentes de populismo no mundo tem indicado que as campanhas eleitorais e governos atuais estão reciclando regularidades de interação em redes digitais (por exemplo, a possibilidade de interagir com um influenciador digital de uma forma "não mediada") e incorporando-as a padrões neoliberais (por exemplo, a desregulamentação da segurança social e do trabalho, punitivismo, milenarismo; ver Lopes, neste volume), de tal forma que a política, o Estado de bem-estar social e as próprias instituições democráticas passam a ser redefinidos. Atualmente, os ataques às instituições do Estado, à ciência, ao meio ambiente e ao Estado de direito são sistemáticos (ver Mercuri \& Lima-Lopes, neste volume, para o caso empírico do ataque no Twitter à greve geral de 2017). No Brasil, como defende Leticia Cesarino (2019), as regularidades na produção de padrões semióticos no WhatsApp e outros meios digitais e a sua disseminação por diferentes públicos fazem parte de uma "ciência do populismo", ou seja, de um processo planejado de produção digital da figura do "povo", encarnado por um líder carismático que se 
opõe a um "inimigo" (ver LACLAU, 2005, e MOUFFE, 2019). A popularidade de Jair Bolsonaro depende em grande parte deste mecanismo digital.

Como apontou Ico Maly (2020) na primeira parte deste dossiê, o populismo não é uma ideologia, mas sim uma relação comunicativa. Theófilo Rodrigues \& Daniel Ferreira, neste volume, demonstram que, independente da orientação ideológica à esquerda ou à direita, o populismo é uma forma de articulação política. (Isso não significa, no entanto, que o grau de participação nesse mecanismo de articulação seja o mesmo: na análise de Rodrigues \& Ferreira, o populismo de Bolsonaro oferece menos possibilidades de construção da agenda política por eleitores do que o populismo do partido Podemos, na Espanha, cuja pauta tem sido horizontal desde o princípio). Na primeira metade do dossiê, Blommaert (2020) descreveu com clareza as principais características das relações comunicativas contemporâneas no campo da política: elas não seguem a imaginação linear do circuito da fala de Saussure ou da esfera pública de Habermas, mas sim redes policêntricas, direcionadas e algorítmicas. Os populismos contemporâneos têm assim se constituído no palco das reconfigurações da esfera pública nas mídias digitais, das affordances dessas mídias (ver Vallada, neste volume; Mercuri \& Lima-Lopes, neste volume), bem como das metamorfoses de construtos interacionais como "verdade" (ver Viscardi, neste volume) ou polidez (ver as formulações sobre a construção política do ódio em Biar \& Paschoal, Silva, Cavalcanti \& Ferreira e Mercuri \& Lima-Lopes, neste volume).

Em linha com a posição pioneira de Moita Lopes, espero que os artigos nesta edição de Trabalbos em Linguística Aplicada ajudem a produzir inteligibilidades sobre as atuais transformações digitais e semióticas da política. Para concluir esta apresentação, devo salientar que eu não teria conseguido organizar este dossiê sem a ajuda de colegas que atuaram como interlocutores no projeto geral ou como revisores por pares. Assim, expresso aqui meu muito obrigado aos/às colegas: Viviane Veras, Ana Cecilia Bizon, Tereza Maher, Cynthia Agra de Brito Neves, Érica Lima, Joel Windle, Marco Jacquemet, Dawn Cunningham, Joana Plaza Pinto, Luiz Paulo da Moita Lopes, Branca Fabricio, Claudiana Alencar, Daniela Palma, e Junot Maia. Agradeço também a Esmeraldo Armando Santos, do Setor de Publicações do IEL/Unicamp, pelo seu brilhante apoio editorial.

\section{REFERÊNCIAS}

BLOMMAERT, J. (2020) Political discourse in post-digital societies. Trabalbos em Linguística Aplicada, v. 59, n. 1, p. 390-403. 
CESARINO, Leticia. (2019) On Digital Populism in Brazil. PoLAR: Political and Legal Antbropology Review. Available at: https://polarjournal.org/2019/04/15/on-jairbolsonaros-digital-populism/

JACQUEMET, Marco. (2019) The Digitalization of the Asylum Process (and the Digitizing of Evidence). In: Hass, Bridget \& Amy Shuman (Eds.) Technologies of Suspicion and the Ethics of Obligation in Political Asylum. Athens: Ohio University Press.

LACLAU, Ernesto. (2005). On populist reason. Londres: Verso.

MALY, I. (2020). Algorithmic populism and the datafication and gamification of the people by Flemish Interest in Belgium. Trabalhos em Linguística Aplicada, v. 59, n. 1, p. 444-468.

MOITA LOPES, Luiz Paulo. (2006) Por uma Linguística Aplicada Indisciplinar. São Paulo: Parábola

MOUFFE, Chantal. (2018) For a left populism. Londres: Verso.

Recebido: 23/7/2020

Aceito: 24/7/2020

Publicado: 27/7/2020 